\title{
An Empirical Study on the Factors Which Affect the Regional Structure of Graduate Education in China
}

\author{
Chuanyi WANG, Haihuan ZHUANG, Jiangxue DAI*, Pei WANG \\ Wuhan University, Institute of Education Science, Wuhan, Hubei, China
}

\begin{abstract}
This paper discusses the factors including culture, economic, politics, population, technology and regional structure of higher education which shaped the regional structure of graduate education and interacted with each other. It has been found that the method of path analysis and effect decomposition is useful and accurate for testing the effect of factors exerted on the regional structure of graduate education. The result suggests that technology, regional structure of higher education, economic, culture, and population have statistical significant effect on the regional structure of graduate education of China, but from higher to lower degree.
\end{abstract}

KEYWORD: Regional Structure of Graduate Education; Factor; Path Analysis; Effect Decomposition

\section{INTRODUCTION}

Graduate education is the high level of higher education in China. It is also a central issue of social science and education research. Regional structure is the state of regional development and the distribution of elements and resources among regions. Similarly, the regional structure of graduate education in China is the regional graduate education development and the distribution of graduate education elements and resources in China. And "region" here means province in China.

The research focuses on investigating the factors affecting the regional structure of graduate education in China. It will investigate the characteristics of interaction of the factors and how they affect the regional structure of graduate education in China.

\section{MODEL ESTABLISHMENT}

As we all know, economy is the most important factor which affects the development of education. The regional structure of graduate education is determined by the regional structure of economy. The influence of economy can be divided into three aspects: (1) the regional economic development has great influence on the supply and demand of the regional graduate education. Usually, the higher the level of the regional economic development, the more supply and demand of the regional graduate education generates. (2) The extent of labor market is driven by the market law. The more transparent the labor market is, the easier the graduate can find a suitable job and realize her/his value. (3) The regional industrial structure interacts with the disciplinary structure of regional graduate education.

Moreover, politics has great power to affect the regional structure of graduate education. In Clark Kerr's opinion, the huge change of university is caused by the power outside, which comes from the Napoleon of France, Germany's Minister of Education, the British Royal Commission and the University Grants Commission, the Russian Communist Party. In China, the politics displays greater power than that in other country. The immigration of university caused by the antiJapanese War(1937-1945), the change of provincial capital cities, the educational policy including input, Graduate School construction , "985" and "211" Project basically form the regional structure of graduate education. On the other hand, the environment of politics will also have an effect on the regional structure of graduate education. The relationship between government and market has close contact to the capital which enters into the graduate education. The legal environment and development of NGO in the region also promote the development of graduate education. However, we could not take the consequence of education policy or major history events in consideration because of the variable characteristic of unpredictable and 
uncontrollable. And we will also fall into the strait of "to illustrate it by itself", so that we are easy to ignore the effect of other variables.

Technology is also connected with the regional structure of graduate education. The center of the technology is coincident with the center of graduate education worldwide. At first the center was German, then, transferred to the US. So did the graduate education. The junction of them is the cooperation in terms of production, study and research. The benefit from the progress of technology can promote the development of regional graduate education while the graduate education supports the innovation of technology. The Silicon Valley in American and the Zhong Guan Chun in China are both typical cases.

Population determines the foundation that the number of students who enter the graduate school in the region. Usually, the larger the population is in the region, especially the population who has got the bachelor degree, the more the graduates accepted. In some sense, the distribution of population is not an ignored factor which affects the regional structure of graduate education.

Like the relationship between root and tree, culture is the invisible power which formulates the state of regional graduate education. If the residents place education on an important role, the opinion pursued the education of higher stage will be more intense. On the other hand, the feature of regional culture will bring up establishment of relevant research center. In Tibet of China, it is very common that graduates study Buddhism of Tibetan but it is hardly seen in other regions.

As we all know, graduate education is the high stage of higher education. Therefore, the regional structure of higher education can be the most direct factor in education system which affects the regional structure of graduate education.

However, we should also take the influence of society outside the education system into consideration. We should not neglect the economic, politics and population etc. has exerted their power on the regional structure of higher education and the power could transfer to the regional structure of graduate education. So theory model in the following figure to describe the interaction path preliminarily.[1]

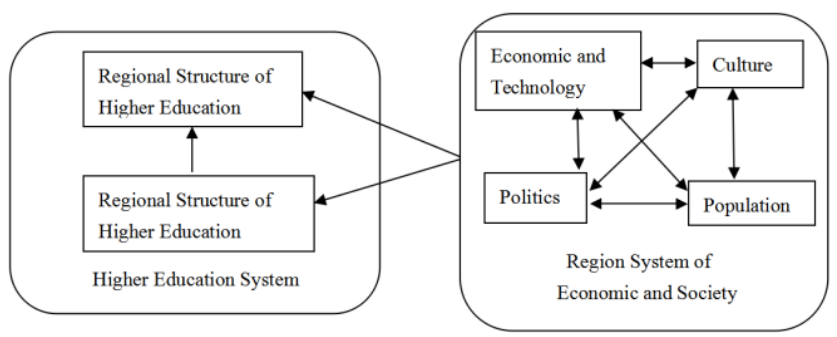

Fig. 1 Caption of a theory model of factors affecting regional structure of graduate education.
We change the theory model into mathematical formulae as follows:

$$
\left\{\begin{array}{l}
G_{i}=\alpha_{0}+H_{i-1}+\sum_{i=1}^{5} X_{i}+\mu_{1} \\
H_{i}=\beta_{0}+\sum_{i=1}^{6} X_{i}+\mu_{2}
\end{array}\right.
$$

$G_{i}$ is regional structure of graduate education in $i$ period. $H_{i-1}$ is the regional structure of higher education in $i-1$ period. $X_{i}$ is the influencing factors which includes economics, politics, population, culture and technology. $\alpha_{0}$ and $\beta_{0}$ are constant, which represent the constant contribution the external world has made to endogenous variable; $\mu_{1}, \quad \mu_{2}$ are random disturbance terms The model is made up of two endogenous variables, five exogenous variables and thirteen parameters.

\section{INDEX SCREENING, DATA AND DESCRIPTIVE STATISTICS}

How can we measure these variables? Maybe more than one index can represent the variable. So we must find the most effective index. At first, we find the most possible index for each variable to keep the comprehensiveness of index.

Then we begin our process of index screening. When a variable contains one index, we regard this index as its best measurement. When a variable contains two indexes, we could use Kurskal-wallis Test to investigate the difference between them. If they have no significant difference, we will choose the index which has the largest sum square of rank correlation. If they have significant difference, we will retain the two indexes. When a variable contains three or more variables, we should standardize the data and cluster the index into several clusters. Then we need repeat the procedure above to screen the best indexes. The detail of calculating is omitted, the result that the best indexes and its descriptive statistics are in the Table 1. The data of Education competitiveness of graduates is quoted from $A n$ Evaluation Report of Postgraduates Education in China. [2] The other data come from China Education Statistical Yearbook. 
Table 1. Descriptive Statistical Results of Screened Indexes

\begin{tabular}{|c|c|c|c|c|c|}
\hline Variable & Index & Unit & \begin{tabular}{|l|} 
Sample \\
number
\end{tabular} & Average & $\begin{array}{l}\text { Standard } \\
\text { deviation }\end{array}$ \\
\hline $\begin{array}{l}\text { Regional structure of } \\
\text { graduate education }\end{array}$ & Education competitiveness of graduates & & 217 & 51.90465 & 25.10317 \\
\hline Culture & Expenditure for culture per capita & Yuan RMB & 217 & 17.12687 & 15.43952 \\
\hline Economic & GDP of provinces & Hundred million RMB & 217 & 7812.162 & 7266.436 \\
\hline Technology & $\begin{array}{l}\text { Research and Development Expenditures in } \\
\text { provinces }\end{array}$ & Ten thousand RMB & 217 & 1064989 & 1368107 \\
\hline Population & Number of people in provinces & Ten thousand RMB & 217 & 4182.71 & 2654.156 \\
\hline Politics & Public expenditure on education in provinces & Thousand RMB & 217 & 2300000 & 17100000 \\
\hline $\begin{array}{l}\text { Regional structure of } \\
\text { higher education }\end{array}$ & $\begin{array}{l}\text { The number of higher education students in } \\
\text { provinces }\end{array}$ & Person & 217 & 595229.9 & 392107.7 \\
\hline
\end{tabular}

*The time span of the data is from 2003 to 2009.

\section{PARAMETER ESTIMATION AND EFFECT ANALYSIS}

We use path analysis to estimate the factors' effect to regional structure of graduate education and interaction. Regression models are interrelated with each other, so a certain degree of correlation may exist in random disturbance. We control the correlation of the exogenous variables. And single equation estimation methods such as ordinary least squares, indirect least squares, two-stage least squares, and even maximum likelihood method may ignore the relationship between equations, making parameter estimation not meet the standard of unbiased. Therefore, we take all the equations as a whole and estimate it with three-stage least squares. We put data into STATA 12.0 and the results are in Table 2:

Table 2. Results of Path Analysis

\begin{tabular}{|c|c|c|c|c|c|}
\hline & & \multicolumn{2}{|c|}{ Equation 1} & \multicolumn{2}{|c|}{ Equation 2} \\
\hline \multicolumn{2}{|r|}{ Dependent variable } & \multicolumn{2}{|c|}{$\begin{array}{c}\text { Regional structure of graduate } \\
\text { education }\end{array}$} & \multicolumn{2}{|c|}{$\begin{array}{c}\text { Regional structure of Higher } \\
\text { education }\end{array}$} \\
\hline & & coefficient & $\mathrm{Z}$ value & coefficient & $\mathrm{Z}$ value \\
\hline \multirow{6}{*}{$\begin{array}{l}\text { Independent } \\
\text { variable }\end{array}$} & Regional structure of Higher education & 0.56 & $3.91 * *$ & & \\
\hline & Culture & 0.17 & $2.09 * *$ & -0.11 & -1.20 \\
\hline & Economic & 0.13 & $1.96^{* *}$ & 0.16 & $2.02 * *$ \\
\hline & Technology & 0.46 & $3.33 * *$ & 0.30 & $2.48 * *$ \\
\hline & Population & -0.20 & -1.85 & 0.41 & $4.36 * *$ \\
\hline & Politics & 0.21 & 1.65 & 0.09 & 0.68 \\
\hline$R^{2}$ & \multicolumn{3}{|c|}{0.7498} & \multicolumn{2}{|c|}{0.8432} \\
\hline
\end{tabular}

* means that the parameters have passed the statistical test on 0.05 significant level.

According to the model parameter, economic, culture, technology and regional structure of higher education have significant positive influence upon the regional structure of graduate education. That is coordinate with the reality of graduate education in China. The graduate program set and review largely connect with the feature of regional culture. For instance, Shandong is famous for Confucius culture. We can see several research center established for the feature of regional culture and recruit the graduates. As power source of scientific and technology progress, graduate education must keep close contact to the technology. We have mentioned above that the cooperation in terms of production, study and research is the junction of the university and industry. So the regional structure of graduate education should take the regional structure of technology into consideration and locate the graduate program according to the demand of technology. However, we should interpret that why the coefficient of politics have not pass the statistical test of 0.05 significant level? First, we must trace to index we screened. The politics is measured by public expenditure on education in provinces measured. But the public expenditure on education usually focuses on the compulsory education of each region. Besides, the graduate education gets the financial support largely from central government not the local government.

On the other hand, the regional structure of higher education is in significant positive correlation with the technology, population and economic. We can see the difference between the regional structure of higher education and graduate education from the 
factors. As the expansion of the scale of higher education, the topic of development of higher education is pursuing the equity, especially in different regions. So development of higher education pays great attention to the opportunity of entering the university. They will put the regional structure of population on a very important role. But graduate education will not regard the population as an important factor as the high stage of tertiary education. It is elite education to some extent. So only in the equation 2 , the population can be a significant factor which affects the regional structure of higher education.

Furthermore, we can compare the effect size among the factors. According to the model parameter, regional structure of higher education, economic, technology and culture are all significant factors. But the effect size is different. The most powerful factor is regional structure of higher education. The second is technology. The economic and culture is almost the same. However, we must not neglect a fact that the population, economic, technology, culture can affect the regional structure through influencing the regional structure of higher education. In order to distinguish the two kinds of effects, we turn to the method of decomposition of effect. We calculate the direct effect, indirect effect and total effect by the help of STATA 12.0. We could see the result in Table 3. It suggests that although culture has comparative higher direct effect the lower correlation with higher education reduce the total effect partly. On contrary, the population has highest indirect effect while it has nothing to do with regional structure of graduate education directly. Regional structure of higher education only has the direct effect as an intermediary variable in higher education system. Technology is the most powerful factor which has the largest size of effect. It has 0.66 per unit direct effect and 0.27 per unit indirect effect. Though economic has significant effect on regional graduate education, it does not reach our expectation. The size of total effect is only 0.24 per unit, less than the technology and regional structure of higher education.

Table 3. Results of Effect Decomposition

\begin{tabular}{|c|c|c|c|c|c|}
\hline Factor & Culture & Technology & Population & Regional structure of higher education & Economic \\
\hline Direct effect & 0.25 & 0.66 & -0.29 & 0.59 & 0.13 \\
\hline Indirect effect & -0.08 & 0.27 & 0.33 & 0 & 0.11 \\
\hline Total effect & 0.17 & 0.93 & 0.04 & 0.59 & 0.24 \\
\hline
\end{tabular}

\section{CONCLUSION}

Based on the theory model establishment, path analysis and effect decomposition, Three conclusions are addressed as follows:

1. The culture, economic, politics, population and regional structure of higher education shaped the regional structure of graduate education and interacted with each other.

2. Economic, culture, technology and regional structure of higher education have significant positive influence upon the regional structure of graduate education directly.

3. Technology, regional structure of higher education, economic, culture, and population have statistical significant total effect, from higher to lower degree, on the regional structure of graduate education of China when we consider the direct effect and indirect effect together.

\section{ACKNOWLEDGMENT}

The research is support by "the 12th Five-years Plan of national science of education the Youth Research topics of the Ministry of Education (Project ID: EIA130339)"

\section{REFERENCES}

[1] WANG C. \& Hu W. Evaluation studies on graduate education system quality: The case of provinces in China. Geomatics and Information Science of Wuhan University, v 37, n SUPPL.1, p 226-229.

[2] Qiu J., An Evaluation Report of Postgraduates Education in China (2011-2012), 1rd ed., Beijing: Science Press, 2011. pp.1. 